Chapman University

Chapman University Digital Commons

ESI Working Papers

Economic Science Institute

$1-2-2019$

\title{
Cooperation Among Strangers With and Without a Monetary System
}

Maria Bigoni

University of Bologna

Gabriele Camera

Chapman University, camera@chapman.edu

Marco Casari

University of Bologna

Follow this and additional works at: https://digitalcommons.chapman.edu/esi_working_papers

Part of the Econometrics Commons, Economic Theory Commons, and the Other Economics Commons

\section{Recommended Citation}

Bigoni, M., Camera, G., \& Casari, M. (2019). Cooperation among strangers with and without a monetary system. ESI Working Paper 19-01. Retrieved from https://digitalcommons.chapman.edu/esi_working_papers/256/

This Article is brought to you for free and open access by the Economic Science Institute at Chapman University Digital Commons. It has been accepted for inclusion in ESI Working Papers by an authorized administrator of Chapman University Digital Commons. For more information, please contactlaughtin@chapman.edu. 


\section{Cooperation Among Strangers With and Without a Monetary System}

\section{Comments}

Working Paper 19-01 


\title{
COOPERATION AMONG STRANGERS WITH AND WITHOUT A MONETARY SYSTEM*[
}

\author{
Maria Bigoni \\ University of Bologna \\ \& IZA
}

\author{
Gabriele Camera \\ Chapman University \\ \& University of Bologna
}

\author{
Marco Casari \\ University of Bologna \\ \& IZA
}

January 2, 2019

\begin{abstract}
Human societies prosper when their members move beyond local exchange and cooperate with outsiders in the creation of wealth. Collaboration of this type presents formidable challenges because interaction is impersonal, reciprocity is unfeasible and trust cannot be easily established. Here we study this cooperation problem by modeling strategic interaction among strangers through an Intertemporal Exchange Game. The setup can be easily implemented in the laboratory to study a variety of cooperation-enhancing institutions. In particular, we study the role of a fiat monetary system by introducing intrinsically worthless tokens that can be offered in exchange for cooperation. The experiments show that a monetary system spontaneously emerges in the laboratory, and is a key institution to promote cooperation among strangers.
\end{abstract}

Keywords: gift-giving, intertemporal trade, macroeconomic experiments, repeated games, social norms.

JEL codes: C70, C90, D03, E02

* This chapter is written for the Handbook of Experimental Game Theory edited by M. Capra, R. Croson, T. Rosenblatt, and M. Rigdon (Edward Elgar publisher), and is partly based on previously published material by the authors. We thank an anonymous reviewer for helpful comments and suggestions. Correspondence address: Gabriele Camera, Economic Science Institute, Chapman University, One University Dr., Orange, CA 92866; e-mail: camera@chapman.edu. 


\section{Introduction}

The vast majority of commercial transactions are monetary, and new developments in cryptography and computing have given rise to digital alternatives to traditional peer-to-peer currency instruments (Camera, 2017). Yet, there is still no consensus on the answer to the question "why does money exist?". Here we present a game-theoretic approach to study monetary institutions in the laboratory, which breaks new ground in addressing this open question.

It is commonly accepted that money serves as a medium of exchange, unit of account, and store of value (Polanyi, 1957), and although this tells us what money does, it does not explain why societies need money to function. The explanation found in standard economics textbooks is that money was created to avoid the difficulties of barter, but this is more of a parable than an explanation. 1 In fact, one would be hard pressed to find anthropological evidence in support of this view (Graeber, 2011; Humphrey, 1985). And on the other hand, the central ingredient of the theory of money is not barter but informational frictions, which basically means difficulties in assessing who owes what to whom (Kocherlakota, 1998, Ostroy, 1973, Townsend, 1987). These frictions stem from interactions that are impersonal-as when people deal with strangers. Without these frictions trade would be easy even if barter were impossible so there money would theoretically have no role to play. Monetary theory asserts that we should not observe monetary trade if information about past conduct can be easily collected and distributed (Corbae et al. 2003 ; Kahn $\sqrt{1 \text { For example the textbook by } \mid \text { Mankiw }}$ (2004) Chapter 29, p. 627-628) states: "Imagine, for a moment, that there was no item in the economy widely accepted in exchange for goods and services. People would have to rely on barter - the exchange of one good or service for another - to obtain the things they need. To get your restaurant meal, for instance, you would have to offer the restaurateur something of immediate value. You could offer to wash some dishes, clean his car, or give him your family's secret recipe for meat loaf. An economy that relies on barter will have trouble allocating its scarce resources efficiently." 
and Roberds, 2005).

Here we discuss laboratory experiments that have tested the empirical validity of the above theoretical postulates. An advantage of the experimental approach is the possibility to uncover causal relationships between the structure of the economic environment, the emergence and the properties of the monetary system. For instance, there are many historical examples of societies that did and did not rely on money - ancient Rome and India used coins for internal trade, while Egypt and pre-Colombian societies did not (Graeber, 2011; Polanyi, 1957)-but it is difficult to establish causal relationships based on this field evidence, due to many confounding factors and profound institutional differences across these societies.

The macroeconomic experiments we discuss do not narrowly mirror a specific monetary model. They are based on a theoretical platform designed to capture the principle of operation underlying any microfounded model of money: enforcement limitations give rise to a severe form of market incompleteness, which makes intertemporal trading agreements difficult to support. . $^{2}$ This economic friction hinders an efficient reallocation of consumption across space and time, and it ultimately motivates the use of media of exchange in a variety of monetary models, for example overlapping generations (Samuelson, 1958), turnpike (Townsend, 1980), trading post (Hayashi and Matsui, 1996. Shapley and Shubik, 1977), or random matching (Diamond, 1984, Hellwig, 1976; Kiyotaki and Wright, 1989). The experimental results have thus wider generality compared to those emerging from experiments tied to a specific

${ }^{2}$ In the words of Keynes "For the importance of money essentially flows from its being a link between the present and the future." (Keynes, 1936, chapter 21, p. 293). This is why money traditionally had no explicit role in the theory of growth, asset pricing, unemployment or business cycles, because in those models intertemporal trading arrangements can typically be enforced. 
model.

Monetary theorists have asserted that money exists only to bridge informational gaps: its unique purpose is to expand the set of payoffs when players cannot monitor counterparts' past conduct (e.g., Huggett and Krasa, 1996. Kocherlakota, 1998, Ostroy, 1973). This view relies on two intertwined-and tacit-postulates. First, money matters only if it is uniquely capable of expanding the theoretical efficiency frontier. If the efficient allocation can be supported without money, then money is inessential ( $\mathrm{Hahn}, 1973)$ and will not be used because - and here is the second tacit postulate -individuals naturally coordinate on efficient play (e.g., Wallace, 2014, footnote 1). This is why barter is a moot problem: if trading histories are public information, then players can support the efficient allocation by incurring and settling debts through an intertemporal exchange of gifts - hence money has no reason to exist even if barter is impossible (e.g., Corbae et al., 2003, p. 737). In a sense, the theory of money tacitly assumes away one of the central problems of game theory: equilibrium selection.

The experiments discussed in this chapter tell a different story, which casts doubts on the empirical validity of these theoretical assertions. They show that money matters for behavioral reasons that are not captured by the theory. On the one hand, subjects often fail to coordinate on efficient play when a monetary institution is unavailable, in large part because there exists strategic uncertainty - a feature that is known to get in the way of attaining efficient outcomes, especially in large groups (Capra et al., 2009, Heinemann et al., 2009: Van Huyck et al., 2007). On the other hand, we observe that monetary trade emerges as an institution that reduces strategic uncertainty, thus facilitating coordination on high-payoff equilibria even in large groups. These empirical findings help to explain why money plays such a prominent role in 
the field.

To study emergence and functions of money in the laboratory we construct an infinitely repeated social dilemma (Friedman, 1971), called the Intertemporal Exchange Game. Multiple players interact in consumer-producer pairs that are randomly rearranged in each period. The producer can unilaterally transfer a valuable good to the consumer. The transfer is socially efficient, as the production cost is below the consumption value. The players' roles alternate over time and their identities remain hidden, hence cooperation amounts to an intertemporal exchange of goods among strangers. Cooperation is one of multiple equilibria (Ellison, 1994, Kandori, 1992).

In this environment we introduce payoff-irrelevant objects called tokens, which can be exchanged for the consumption good quid pro quo. If producers transfer the good only in exchange for a token, then tokens become fiat money and a monetary system emerges. Otherwise, tokens remain valueless. The tokens' supply is fixed and chosen to ensure that a monetary system is feasible. However, the introduction of tokens does not remove any strategy available without tokens, and their use is entirely voluntary. By design, tokens merely expand the strategy set and their use cannot expand the efficiency frontier. In fact, not only payoffs cannot be improved by using money, but can actually be lowered if liquidity constraints are binding, i.e., if it happens that a buyer has no money to offer a seller. These design features remove the main theoretical reason for the use of money, and allow us to concentrate on studying its behavioral role.

Our choice to cast the problem of monetary exchange within a gametheoretic framework with a finite number of players has both advantages and disadvantages. On the one hand, the use of a finite population is needed for practical reasons to bring infinite macroeconomic models into the lab Alipran- 
tis and Plott, 1992). Studying monetary systems in the laboratory allows us to manipulate institutional factors, to eliminate confounding factors that characterize field data, and to understand what principles are in operation (Plott, 2001). On the other hand, in a finite population individual actions have a strategic impact (Kovenock and De Vries, 2002; Levine and Pesendorfer, 1995) and players have a positive probability to meet more than once, which also affects the dynamics of the game (Camera and Vesely, 2003). These type of strategic considerations are generally not found in monetary models, because those models invariably create economies of strangers by assuming infinite populations. This second consideration explains why in the design we made a specific effort to remove reputation effects, by appropriately manipulating informational flows and interaction over time.

We proceed as follows. Section 2 contains the design and some important theoretical considerations. Section 3 gives an overview of the main results about cooperation among strangers, when monetary systems cannot emerge. Section 4 describes how the game changes when we introduce tokens, and Section 5 present the experimental results. Section 6 discusses a new experiment, where there is an oversupply of tokens. Finally, Section 7 concludes.

\section{The Intertemporal Exchange Game}

This section opens with a description of the game setup without any monetary institution, then presents theoretical considerations about the equilibrium set, and finally illustrate its experimental implementation..$^{3}$

The cooperative task. Our prototypical cooperative task is a helping game between an active producer and a passive consumer (see Table 1). The

\footnotetext{
${ }^{3}$ This section is largely based on material from Bigoni et al. (forth.).
} 
producer is endowed with a good while the consumer has no endowment. The consumer has the largest benefit from consuming the good, while the producer has the option to unilaterally transfer the good to the consumer. If this occurs, then we say that the producer "helps" the consumer, or, equivalently, cooperates. Otherwise, we say that the producer "does not help" or, equivalently, defects (Nowak and Sigmund, 1998).

Table 1: The Helping Game.

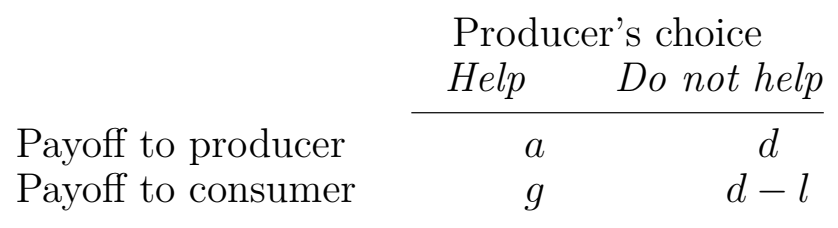

Notes: In the experiment $g=20, d=6, l=2, a=0$ (Bigoni et al., forth.)

If the producer helps, then her payoff is $a$ while the consumer's is $g$. If no help is given then the consumer's payoff is smaller, $d-l$, while the producer payoff is larger, $d>a$. We retain the assumption that helping maximizes total payoffs, i.e., $g+a>2 d-l>0$. This means that cooperation is socially efficient because it maximizes surplus, which is simply $g+a-(2 d-l)$. Note, however, that if this interaction is not repeated then the producer has no incentive to help because defection is the dominant strategy.

The supergame. Players repeat the stage game for an infinite number of rounds, and discount payoffs according to a parameter $0<\beta<1$. After each round of play, both players observe the outcome. There is constant population of $\mathrm{N}$ players ( $\mathrm{N}$ even), and in each round half are producers and half are consumers. Roles alternate deterministically every round. If there is cooperation in every meeting over the course of the supergame, then the 
alternation in roles implies that there is an intertemporal exchange of help. This outcome is clearly efficient because surplus is maximized in every meeting.

Strangers. Players interact as strangers because opponents change at random every round and their identities are hidden (Figure 1). Hence, players can never identify their opponent. Moreover, the observable information after each round preserves the anonymity of interaction. In this setup, there is no possibility for anyone to engage in relational contracting. Moreover, a player cannot build a reputation. Put simply, we say that interaction is impersonal.

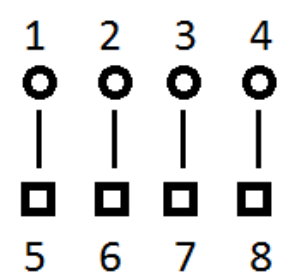

round 1

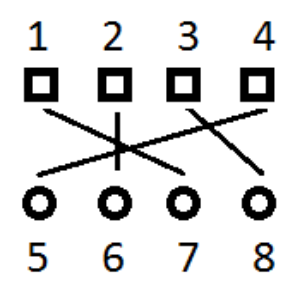

round 2

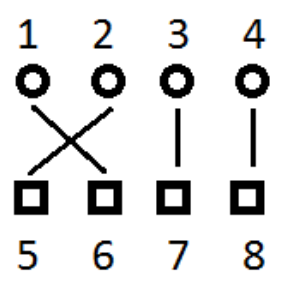

round 3

Figure 1: Strangers' matching.

Notes: Example of pairwise meetings in a group of $N=8$ subjects. Circles and squares denotes different roles; numbers indicate subject's ID, which remains private.

This contrasts with a situation where players interact as partners, because the opponent remains the same over time, and it is possible to establish reputation. In this case, interaction is personal.

Information. Players observe a common signal about the actions taken in the round, which is a form of public monitoring. More specifically, at the end of every round every player is able to see a statistic that reports the distribution of outcomes in the population. For example, players could be informed if all 
pairs resulted in identical outcomes or not, or they could be provided a numeric value about the mean cooperation level in the population. This introduces a shared element of history among all players in the population, i..e, of public monitoring, while retaining a strangers setting. The statistic is important because it can publicly reveal whether or not a defection occurred anywhere in the population.

Theoretical considerations. One can show that full cooperation is an equilibrium outcome for any population size $N$. The idea is simple: given the kind of public monitoring we have assumed, we can consider a strategy which threatens an immediate, and harsh, community-wide punishment if anyone refuses to act cooperatively at any point in time. Specifically, we consider the following strategy:

Definition 1 (Cooperative strategy). Consider the player in her role as a producer. The player helps in round 1 and in all subsequent rounds only if her information is consistent with every other producer having helped, up to that point. Instead, if she has knowledge of some defection, then the player will permanently stop helping consumers.

We say that a social norm of intertemporal exchange of help-or, equivalently, of intertemporal cooperation - emerges whenever every player in the population adopts this cooperative strategy. A social norm of cooperation has two parts. First, there is a "rule of cooperation," i.e., always help if others do the same. Second, there is a "rule of punishment," i.e., stop helping if someone takes an uncooperative action. This rule of punishment serves as a sanction that leads to permanent defection in the whole population. It turns out that when the discount factor is sufficiently large, then this sanctioning scheme can ensure the sustainability of full cooperation in subgame perfect equilibrium. 
In equilibrium, the payoff to a producer is denoted

$$
v_{0}:=\frac{a+\beta g}{1-\beta^{2}},
$$

while the payoff to a consumer is denoted

$$
v_{1}:=\frac{\beta a+g}{1-\beta^{2}} .
$$

Note, due to the deterministic alternation between helping earning $a$, and receiving help earning $g$, in cooperative equilibrium consumers have a greater payoff than producers, i.e., $v_{1}>v_{0}$.

To demonstrate existence of equilibrium we start by showing that the social norm provides sufficient incentives for producers to not deviating from the rule of cooperation in equilibrium. That is to say, producers prefer to help as opposed to defect. To do so, we must verify that in equilibrium, no producer can increase her payoff by refusing to help a consumer, thus moving off equilibrium. Note that if a producer defects in some round, and everyone follows the social norm of cooperation, the she will earn $d$ instead of $a<d$, but will also trigger a complete stop of cooperation forever after. The implication is that the payoff to a producer who moves off-equilibrium is

$$
\hat{v}_{0}:=\frac{d+\beta(d-l)}{1-\beta^{2}}
$$

Note that this corresponds to the payoff associated to infinite repetition of the static Nash equilibrium, in which no one ever cooperates (which is also an equilibrium of the supergame). Moving off equilibrium is thus suboptimal when $v_{0} \geq \hat{v}_{0}$. It is easily demonstrated that this requires

$$
\beta \geq \beta^{*}:=\frac{d-a}{g-d+l} .
$$


Note that the player suffers a cost $d-a$ from helping when she is a producer. However, she attains surplus $g-d+l$ as a consumer, in cooperative equilibrium. Hence, one can interpret $\beta^{*}$ as the cost-benefit ratio from cooperation.

To complete the proof, we must also show that the social norm of cooperation ensures that it is optimal to punish off-equilibrium, by never again cooperating in any meeting. This is obviously true because any deviation from the rule of cooperation is immediately made public. It follows that if everyone adopts the cooperative strategy in Definition 1, then no player has a reason to cooperate off-equilibrium because not helping is the best response to every producer always choosing "do not help." We summarize this discussion in the following proposition:

Proposition 1. If $\beta \geq \beta^{*}$, then the social norm of cooperation supports the efficient, fully cooperative outcome in subgame perfect equilibrium.

A remark may be helpful. The requirement that $\beta \geq \beta^{*}$ is sufficient for existence of cooperative equilibrium, and it is also necessary (or, otherwise deviating in equilibrium is optimal). However, multiple equilibria exist in this supergame, which include full defection (as seen above) and equilibria with partial cooperation (e.g., start cooperating only after 10 rounds of play have elapsed). It is true that full cooperation is socially efficient, but this does not guarantee that players will coordinate on this outcome instead some other outcome with lower efficiency. That is to say, there is strategic uncertainty because many outcomes are consistent with equilibrium.

Design. The supergame has an uncertain duration governed by a random continuation rule (Roth and Murnighan, 1978). There is a fixed number $T \geq 1$ of rounds, following which an additional round is played with probability $\beta$. Given the discussion above, we interpret this probability as the discount fac- 
tor of a risk-neutral player. To implement this feature in the experiment, at the end of each round a number is randomly drawn by a computer program, from a uniform distribution over the natural numbers between 1 and 100 . The supergame continues into an additional round as long as a number less than or equal to $100^{*} \beta$ is selected. Otherwise, the supergame ends. At the end of each round all participants in the group observe the number drawn, which informs them about the end or continuation of the supergame. Every participant played five separate supergames within a session. Within each supergame, subjects interacted in "groups." In every round of a supergame, new pairs of consumers and producers were formed within a group. At the beginning of each supergame new groups were formed so that no two players ever interacted for more than one supergame. The experiments were run at Purdue University, University of Iowa, and Chapman University with undergraduates volunteers. Every player participated in only one session. Instructions employed a neutral language, they were read aloud to subjects, and involved no deception. Subjects privately received cash payments at the end of the session, which were on average well above the minimum wage.

\section{Main results without money}

Here we present experimental results about the ability of strangers to cooperate in the absence of institutions such as a monetary system. In general, subjects did not fully trust that other subjects in their group of strangers would return a current gift of help later in the supergame. Realized cooperation rates were far from optimal (53.3\% on average) and point toward the difficulty of coordinating on efficient Nash play instead of on other Pareto-inferior equilibria $4^{4}$

\footnotetext{
${ }^{4}$ Recall that the cooperation rate is proportional to the efficiency level of the economy.
} 
Similar outcomes have been observed in several experiments, which suggests the existence of a wide scope for institutions to promote cooperation (Bigoni et al. forth.).

Partners cooperate more than strangers. From a theoretical standpoint, interacting among partners or strangers does not affect the efficiency frontier, as long as there is public monitoring of defections, as when every player in the population can be immediately informed about the occurrence of a defection anywhere in the economy (Abreu et al., 1990). However, from a behavioral standpoint, this can make a large difference in the ability to cooperate. Experimental evidence from Camera et al. (2013a) shows that partners in a fixed pair cooperate more than strangers who interact in random pairs 5 The cooperation rate drops from $70.7 \%$ in partners, to $49.1 \%$ in groups of four strangers.

One obstacle to achieve cooperation among strangers is the impossibility of direct reciprocation, which is known to have a very strong behavioral impact (Fehr and Gächter, 2000). Another possible obstacle is lack of communication. In related experiments with prisoner's dilemma games (Camera et al., 2013b) we found that free-form communication helped to support efficient play. However, structured communication did not help solve the problem of cooperation among strangers, because it was used strategically by free-riders to exploit cooperators. The focus of this chapter is therefore on environments where it is difficult to support cooperation among strangers.

Group size matters. Field evidence on the impact of group size on cooperation is ambiguous, as many factors co-vary with group size. Typically,

${ }^{5}$ Note that the design in Camera et al. (2013a) is slightly different from Bigoni et al. (forth.), as illustrated in Table 2 
returns from cooperation are lower in small groups - due to reduced scope for specialization-but members can monitor each other better than in large groups and can more easily communicate. Experiments can remove these confounds.

Monitoring others is a key requirement to sustain cooperation (Levine and Pesendorfer, 1995), and in the field observing everybody else's actions is more difficult in large groups. We set up an experiment where monitoring is equally accurate in small and large groups by making participants observe the fraction of cooperators in the group (Camera et al. 2013a). Once confounds due to monitoring and returns from cooperation are removed, the observed cooperation rates in the experiment still decline as groups size increases from 4 to 8 , to 32 (see Figure 2). As groups get larger, subjects are less and less able to enforce common rules for the voluntary provision of help. ${ }^{6}$

Cooperation may also suffer due to strategies' miscoordination. According to the theory of repeated games, a group can sustain cooperation by coordinating on a common rule of behavior. When group members are randomly drawn from a generic population, large groups are more likely to be heterogeneous than small groups, hence they are less likely to adopt a common rule.

Another factor that differentiate small and large groups is the frequency of

${ }^{6}$ This trend is opposite to that found in experimental studies of public good games, which generally report higher cooperation in larger groups. The study in Isaac et al. (1994) experimentally explores a voluntary contribution mechanism in groups of size 4, 10, 40 and 100 , and reports that a group's ability to provide the optimal level of a pure public good does not seem to be inversely related to group size. In particular, small groups provide the public good less efficiently than larger groups when the marginal per capita return from the group account (MPCR) is kept constant, and there is a positive correlation between MPCR and efficiency in small groups but not in large groups. Nosenzo et al. (2015) find a positive effect of group size in a voluntary contribution mechanism game with 4 and 8 group sizes, but only in a low MPCR condition. When the MPCR is high they observe a negative group size effect. In the design, however, in larger groups the social return of an individual contribution is generally higher than in small groups, which biases the results in favor of cooperation. 
interaction with a given player. We will turn to this issue next.

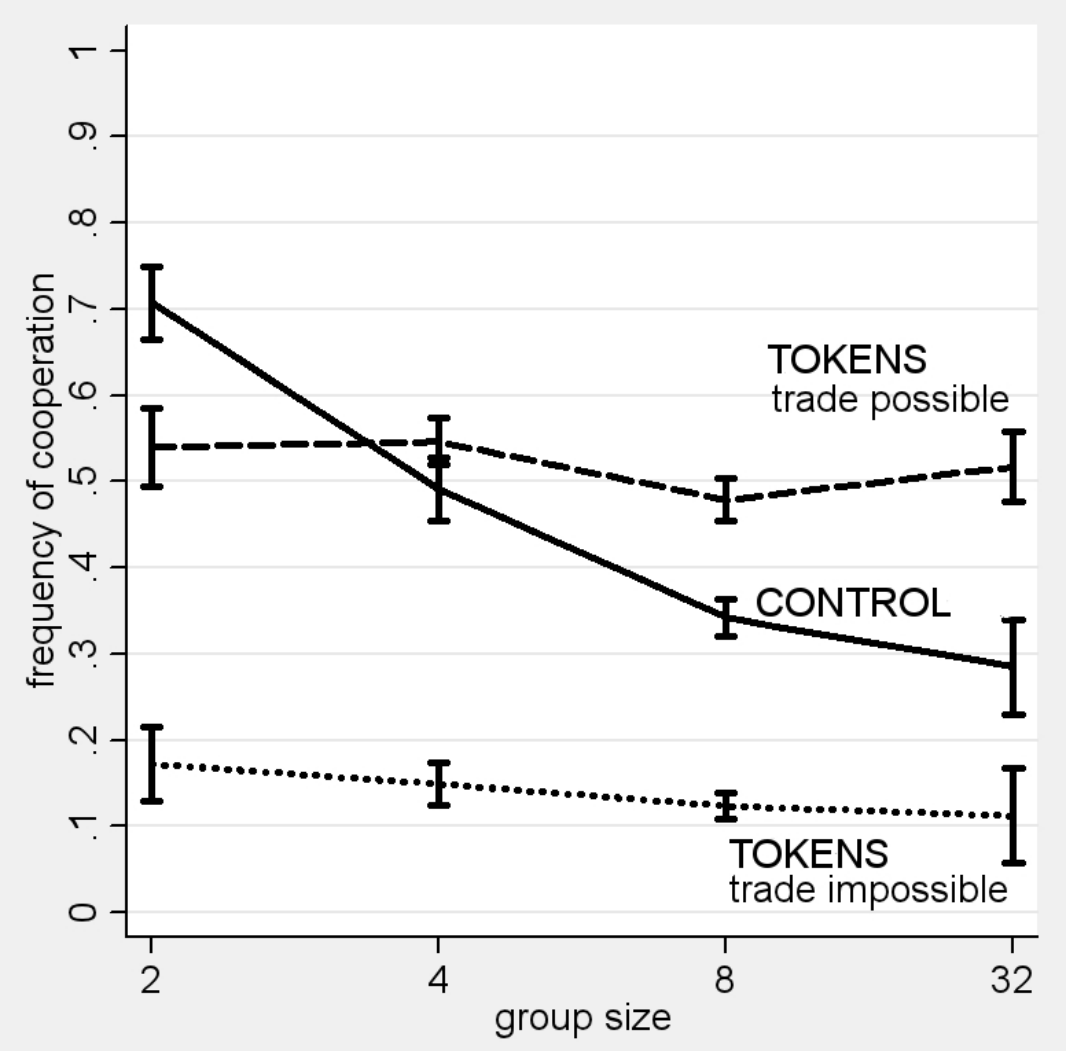

Figure 2: Cooperation and group size.

Notes: The lines represent the average frequency of cooperation, i.e., the fraction of encounters in which the producer helps the consumer. The source is Camera et al. (2013a), where parameters are: $g=20, d=8, l=0, a=2$. In the Control condition, cooperation declines as groups get larger, while in the Tokens condition it remains constant. For the Tokens condition: the dashed (dotted) line considers encounters where trade was (im)possible. In large groups $(N>2)$, cooperation under the Tokens conditions (trade possible) rises relative to the Control condition. The error bars represent the standard error of the mean. The unit of observation is the frequency of cooperation in a group of $N$ players, in a cycle.

Personal interaction facilitates cooperation. Personal interactions in experiments typically involve a fixed set of players called partners, but inter- 
actions can remain personal also with changing counterparts, as long as identities and past actions are observed. With changing counterparts the frequency of interaction is lower than in a partner setting, but relational contracting is still possible. One can test the effect of personal vs. impersonal encounters in a setup of changing counterparts - which holds constant the frequency of interaction - by simply keeping or removing information on the identity and the history of players.

The experiment in Camera and Casari (2017) studies monitoring institutions in groups of four strangers playing an intertemporal exchange game. In one treatment, each producer encounters an anonymous consumer and can pay a cost to obtain an accurate record of her past actions. In another treatment, consumers can pay a cost to make the producer's action publicly available to future counterparts. These monitoring institutions provide information about the consumer's past conduct while hiding her identity. Neither of these monitoring institutions significantly improves cooperation rates in the experiment, as compared to a treatment without monitoring (48.2\%). The cooperation rates are $37.5 \%$ and $49.4 \%$, respectively.

In another experiment with a population of $N=4$ players who meet in pairs in random encounters to play a prisoners' dilemma we observe levels of cooperation remarkably higher when interaction is personal compared to impersonal (81.5\% vs 58.6\%-59.5\%, Camera and Casari, 2009). This result provides strong evidence about an inherent difficulty in supporting cooperation when interaction is impersonal.

Robustness checks. It is possible that the aforementioned results on cooperation are specific to features of the design, such as the structure of stage game, the payoff matrix and duration of the supergame. These design fea- 
tures have been varied across a battery of studies, as summarized in Table 2. All of these variations preserved the theoretical possibility to support full cooperation in equilibrium. In the laboratory, none of these variations induces qualitative differences in cooperation rates.

Specifically, we studied two variants for role alternation. In the intertemporal cooperation game described in Section 2, only half of the players make a choice at any given point in time. In the present study and in Bigoni et al. (forth.) roles deterministically alternate across rounds; in other experiments, we considered random alternation of roles (Camera and Casari, 2014, 2017, Camera et al., 2013a, 2016). Random role alternation tends to reduce coordination on the efficient outcome, especially when differences in past roles are made salient to subjects. The reason is that producers condition their choices on payoff-irrelevant differences in past roles (Camera et al., 2016).

The duration of the supergame has fundamental implications for the incentives to cooperate. In the experiments surveyed in Table 2, the supergame included a fixed number of rounds (which ranges from 1 to 20), after which the supergame's continuation depended on random draw from a uniform distribution (continuation probabilities ranged between 0.75 and 0.95 ).

Changes in the payoffs matrices that do not theoretically prevent full cooperation as an equilibrium outcome may impact cooperation rates in the lab (Dal Bó and Fréchette, 2011; Fudenberg et al., 2012). In previous experiments payoffs in case of a defection were either symmetric $(l=0)$ or asymmetric $(l>0)$, and returns from cooperation ranged from $38 \%$ to $150 \%$ (see Table 2).

Results on cooperation among strangers are also robust to the structure of the stage game. The experiment in Camera and Casari (2009) considers a prisoner's dilemma, instead of a helping game where only half of the players make a choice in each period. 


\section{Introducing Money in the Game}

We introduce tokens in the Intertemporal Exchange Game to study the emergence and properties of monetary systems. Tokens are intrinsically worthless and indivisible objects that are available in fixed supply from the beginning of the supergame, when we give one or more tokens to each initial consumer. The overall number of tokens introduced is made known to all players. We also inform players that the supply of tokens never changes during the course of the supergame because no one can produce tokens nor dispose of tokens. If a consumer has a token, then she can keep it or transfer it to the producer to whom she is matched; instead, if a producer has a token then she cannot transfer it to anyone. Tokens can be carried over to the next round, and vanish at the end of the supergame. In this setup, only one token can be transferred in a pair, hence, prices are fixed.

Adding these tokens has the immediate consequence of expanding the set of possible actions relative to the original helping game without tokens. In doing so, we follow the basic layout of a monetary model: spot monetary trades are easily enforceable so players can avoid outcomes that are not mutually desirable. Simply put, monetary trade takes the form of a direct mechanism which ensures immediate compensation for an agreed-upon delivery (of money or goods). Our design must retain this feature since doing otherwise would mark a fundamental departure from monetary theory $]^{7}$

${ }^{7}$ In the words of Starr "without some requirements of this sort, there is no point in discussing media of exchange" (Starr, 1972, p.294). 


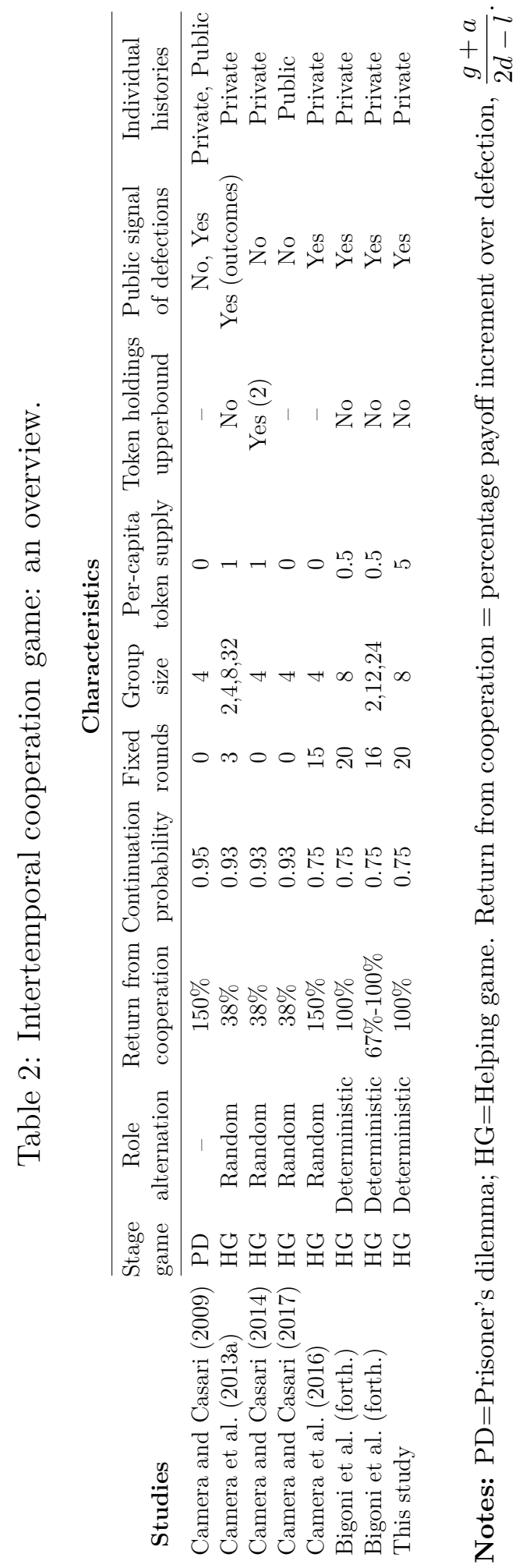




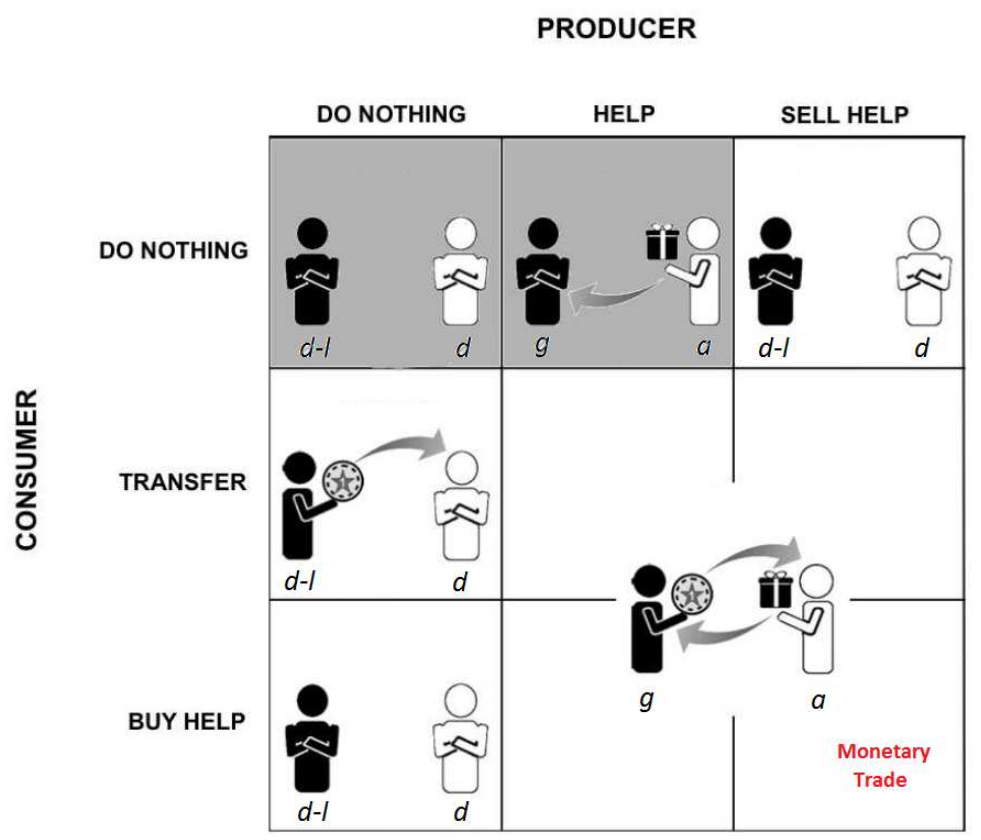

Figure 3: The Monetary Game.

Notes: In the experiment $g=20, d=8, l=0, a=2$. Actions had neutral labels in the experiment.

When the consumer has no tokens, the stage game reverts to the initial helping game described in Table 1 (shaded area in Figure 3). That is to say, credit markets remain unavailable as in the original game. Instead, when the consumer has tokens producer and consumer have the possibility to trade in a meeting, using a direct mechanism. We use Figure 3 to show how. The consumer who has some tokens now has a non-empty actions set, as opposed to a consumer without tokens. The consumer has always the option to do nothing, i.e., to keep her token(s). However, she can also chose to either transfer a token to the producer, i.e., to unconditionally give one of her tokens to the producer, or buy help, i.e., to make the token transfer only upon receiving help. For the 
producer things also change because she has an additional option: she can choose to sell help, i.e., to help upon receiving one token from the consumer. In this scenario, each pair of choices is associated with a unique outcome, which is reported in Figure 3 along with the relevant payoffs.

The fundamental addition is that now cooperation can be mediated by a direct mechanism. This occurs if the producer chooses "sell help" and the consumer chooses "buy help," effectively amounting to a form monetary exchange. Now notice that this same outcome can also be implemented without resorting to a direct mechanism. All we need is that the producer chooses help and the consumer chooses transfer. Note that either way there is no possibility to signal a desire to cooperate before the counterpart takes their action: matched players always make their choices independently and simultaneously.

It is important to recognize that the addition of tokens leaves producers entirely free to unconditionally help, as they were able to do in the original token-less game. Consumers are always free to ignore tokens as well. That is to say, the availability of tokens does not force players to use them. Moreover, since tokens are intrinsically worthless, as long as full cooperation is an equilibrium in the game without tokens, then adding tokens does not expand the efficiency frontier, as we discuss in more depth below. Specifically, we demonstrate that in this augmented setup a monetary system can emerge because there exists an equilibrium where players trade tokens for help. In this case, tokens assume the role of fiat money, and endogenously become valuable, because they enable players to obtain help in future encounters. However, tokens may also remain worthless because there always exists another equilibrium where agents ignore the tokens and continue to play the Intertemporal Exchange Game as they did in the control treatment. In such case, no monetary system will develop. 
Theoretical considerations. In this section we show how the use of tokens can sustain the efficient, fully cooperative outcome. Before doing that, however, we emphasize that the introduction of payoff-irrelevant tokens does not eliminate any of the equilibria possible in the original Intertemporal Exchange Game. The reason is that tokens have no intrinsic value and their introduction does not affect the payoff matrix. Therefore, it should be clear that equilibrium strategies that ignore tokens, such as the cooperative strategy in Definition 1 . are always available to players. However, cooperation can also be attained by basing actions on one's role and the balance of tokens in the meeting. We call this strategy the "monetary trade strategy" because help is exchanged for a token, and is not given unconditionally. As a consequence, help is never given in meetings where the consumer has no tokens 8 Specifically:

Definition 2 (Monetary trade strategy). Fix a round. If the player is a consumer with a token, then she chooses to transfer one token upon receiving help. If the player is a producer, then she chooses to help upon receiving a token only if she does not have a token, and chooses "do not help" otherwise.

Several remarks are in order. First, it should be obvious that a consumer without a token has an empty action set so the monetary trade strategy specifies no move for a player in that state. Second, note that the monetary trade strategy is Markov, and does not depend on history of play. In particular, the intertemporal exchange of help is not based on the threat of a community-wide punishment scheme. In fact, observation of any defection has no impact on the way the player will act in the continuation game.

The uniform adoption of this strategy by every player ensures that every meeting is a trade meeting in which a consumer has one token and the producer

${ }^{8}$ Depending on the distribution of tokens in the economy, there may be meetings where monetary trade is possible (or, feasible) and meetings where it is not. As we will see below, the situation depends on the constrains imposed on upper bound on token holdings and on whether or not the consumer has no tokens. 
has none. if so, then in every trade meeting there is a quid-pro-quo exchange of one token for help. The resulting outcome is called monetary trade because, as in the Turnpike model of Townsend (1980), tokens serve the role of a medium of exchange in pairwise encounters. Payoffs under monetary trade coincide with the payoffs $v_{0}$ (for a producer) and $v_{1}$ (for a consumer) that we derived under the social norm of cooperation.

It is easy to demonstrate that if the social norm of cooperation is an equilibrium, then monetary trade is also an equilibrium. To show it we must prove that in equilibrium the consumer has an incentive to spend her token to buy help, which is always true because the only other option for the consumer is to earn zero payoff, in that meeting. On the other hand, the producer must also have an incentive to sell help for a token when she has none. Since the producer earns $a$ by selling, instead of $d>a$ by not helping, there is an incentive to sell only if she attaches enough value to the help she will receive in the future, when she can spend the token. This requires a sufficiently large discount factor $\beta$.

Demonstrating this requires a bit more work than in the case of the social norm because equilibrium deviations alter the distribution of tokens, at least temporarily. To see this note that if, in equilibrium, a producer refuses to sell for a token this round, then the consumer will enter next round as a producer with a token, while the producer will become a consumer without a token. Therefore, for simplicity, we consider the best-case scenario where the distribution of tokens goes back to equilibrium after two rounds of play. This will happen if the deviator producer meets the same counterpart two periods in a row. Here, the incentive to deviate is the smallest for a producer because the monetary strategy is time-invariant. Hence, two rounds after the initial deviation occurs the entire group will be back in an equilibrium situation, with 
every producer being without tokens, and every consumer having one token. Here, the payoffs will once again be $v_{0}$ and $v_{1}$ for producers and consumers.

Hence, suppose a one-time equilibrium deviation for a consumer: she refuses to spend her token. This lowers her current payoff to $d-l$ from $g$ and leaves her with a token in the next round, when she will be a producer. At that point she will revert back to following the monetary trade strategy, so she will not help (she has already one token to spend). In the best-case scenario, the deviator meets the same player in two consecutive rounds. Since roles alternated deterministically, the distribution of tokens is back at equilibrium two periods after the initial deviation, which is when the initial deviator has a continuation payoff of $v_{1}$. It follows that the consumer will not deviate if

$$
d-l+\beta\left(d+\beta v_{1}\right) \leq v_{1}=g+\beta\left(a+\beta v_{1}\right),
$$

where the left-hand side describes the best-case scenario depicted above. The inequality always holds because $a+g>d+d-l$.

The discussion for a producer is similar. Consider an equilibrium deviation in which she refuses to sell help for a token. Her defection gives her payoff $d$ instead of $a$, and in the best-case scenario changes the distribution of tokens only temporarily, for one round. Indeed, the producer will be a consumer without money in the following round. Since everyone else follows the monetary trade strategy, she will not be able to receive help (earning $d-l$ ) and will be again have a chance to sell for a token two rounds later, for a continuation payoff of $v_{0}$. Assuming that this deviator meets the same person in two consecutive periods, then the tokens' distribution is back at equilibrium two periods after the initial deviation. The implication is that the producer will prefer to sell 
help for a token as long as

$$
d+\beta\left(d-l+\beta v_{0}\right)<v_{0}=a+\beta\left(g+\beta v_{0}\right)
$$

which holds whenever $\beta \geq \beta^{*}$. The lower bound $\beta^{*}$ is the same as under the social norm because in monetary equilibrium refusing to help prevents the producer from receiving a token and, therefore prevents her from receiving help in the following round $!^{9}$

We summarize this discussion in the following Proposition.

Proposition 2. If $\beta \geq \beta^{*}$, then monetary trade supports full cooperation as an equilibrium.

We conclude with an important observation: monetary trade does not expand the payoff set because the efficient outcome is part of the equilibrium set even if tokens are absent (as demonstrated earlier). It follows that if players select their equilibrium play based on an efficiency criterion, then tokens have no reason to exist or to be exchanged for that matter: in the language of monetary theory they are "inessential" (Hahn, 1973).

Design. We endowed each initial consumer with 1 token and each producer with 0 so there is a fixed supply of 4 tokens. This implies that, under monetary trade, in every round all consumers have one token and all producers have none. In our set-up, token transfers can take place only if the consumer has at least 1 token. With a supply of 4 tokens monetary exchange is possible in each meeting, in monetary equilibrium. Off-equilibrium, consumers without tokens make no choice at all, but a producer can still help them unconditionally if she wants to, as in the original game without tokens. In this case, we say that

${ }^{9}$ Off equilibrium, a producer might have more than one token. In that case it is not optimal to accept another due to the deterministic alternation in roles. This is demonstrated in Bigoni et al. (forth.). 
trade is impossible and the decision situation is identical to that in the Control condition.

A supply of exactly four tokens per economy is optimal for two reasons. On the one hand, with less tokens, there are encounters in which monetary trade is not feasible in monetary equilibrium. This is undesirable because it induces inefficiency in monetary equilibrium. On the other hand, with more tokens, the existence of a monetary equilibrium may be compromised, because prices are fixed. By design a producer cannot ask for more than one token and a consumer cannot offer more than one. This nominal price rigidity implies that a producer with tokens has less of an incentive to cooperate for one more token, if she already has some tokens to spend in the next round.

Each player is always informed about the counterpart's possession of tokens. However, the exact number of tokens held by the counterpart is not revealed in order to preserve anonymity and identification of counterparts, and also to reduce the complexity of the decision task. Hence, before making their choice, subjects know whether trade is possible or impossible in the encounter and cannot adopt strategies that condition on the number of tokens held by the counterpart. Notice also that the availability of tokens cannot augment subjects' ability to recall their own past decisions (e.g., as in the accounting system studied in Basu et al., 2009) as compared to the design without tokens, because the subject can always access an electronic record of her past decisions with or without tokens.

\section{Main results from money experiments}

When given the opportunity to engage in monetary trade, experimental economies substantially alter their pattern of behavior. This section illustrates the em- 
pirical findings in terms of the emergence of a monetary systems, cooperation levels, and other behavioral roles of fiat money ${ }^{10}$

Monetary systems endogenously emerge. In the majority of monetary experiments subjects are constrained to either exchange goods for money, or to remain in autarchy (Camera et al., 2003; Deck et al., 2006; Duffy and Ochs, 2002; Huber et al., 2014; Lian and Plott, 1998; Marimon and Sunder, 1993 , 1994 McCabe, 1989). On the contrary in our experiments subjects can make unilateral transfers, and a monetary system may or may not endogenously emerge because the use of tokens in entirely voluntary and not needed to attain efficient outcomes (see also Duffy and Puzzello 2014 for an application of this approach to a specific model of monetary exchange). In the experiments we discuss below, tokens endogenously emerged as fiat money. Subjects valued tokens because they facilitated the intertemporal giving and receiving of cooperation. The data exhibit patterns of behavior coherent with those associated with a monetary economy. In the experiment cooperation took the form of a quid pro quo exchange of help for a token.

Buyers were not willing to transfer a token unless they were sure to be compensated with help. Sellers were not willing to provide help unless they were sure to be compensated with a token. This evidence suggests that subjects attributed value to intrinsically worthless tokens.

Recall that in some encounters, the exchange of tokens was impossible (Section 4). In the experiments, encounters with impossible trade accounted for a sizable fraction of the total (for $\mathrm{N}=4,32.6 \%$ in Camera and Casari, 2014

\footnotetext{
${ }^{10}$ In this section, we will primarily focus on experimental results that emerge from encounters where monetary trade is possible, differentiating them from the case when trade is impossible, when relevant. According to the experimental design monetary trade is impossible when consumers have no tokens. This feature is relevant because it allows us to differentiate behavior of participants when they can and cannot exchange tokens.
} 
and $39.5 \%$ in Camera et al. 2013a).

In economies of $\mathrm{N}=4$, there was a token transfer in $67.5 \%$ of the encounters in which trade was possible in Camera and Casari (2014) and 51.5\% in Camera et al. (2013a). In economies of $\mathrm{N}=8$, there was a token transfer in $62.9 \%$ of the encounters in which trade was possible in Bigoni et al. (forth.) and $43.4 \%$ in Camera et al. (2013a).

A common objection to this type of experimental evidence is that participants are used to monetary exchanges in the field and they mindlessly adopt the same habit in the lab. A closer look at the data rejects this interpretation. First, the adoption of monetary exchange, although widespread, is far from universal. Second, the use of money as a medium of exchange steadily increases with lab experience (Bigoni et al., forth.). Hence, subjects gradually develop a monetary trade convention within the lab environment. Third, as we will see in Section 6, no monetary convention emerges where it is theoretically unsustainable.

Money supports cooperation in large groups. When participants can engage in monetary trade, cooperation rates do not decrease even when the size of the group increases. The average frequency of cooperation is $52.1 \%$ (computed attributing equal weight to each condition $N=2,4,8,32$ ). The dashed line in Figure 2 reports disaggregated data; there is no significant difference across group sizes (Camera et al. 2013a).

The possibility of monetary trade significantly boosts cooperation (hence, surplus) in large groups where $N=32$ : without money (Control condition) the frequency of cooperation is $28.5 \%$, and it jumps to $51.7 \%$ with money (Tokens condition) when we consider only the matches in which trade is possible. Monetary trade has a similar impact for smaller groups, although the magni- 
tude is lower ( $49.1 \%$ vs. $54.6 \%$ for $\mathrm{N}=4$, and $34.2 \%$ vs. $47.9 \%$ for $\mathrm{N}=8$ ). The opposite holds true when participants interact as partners, i.e., $N=2$ was the group size. In this case, individuals cooperate significantly less in the Tokens than in the Control condition (54.0\% vs. $70.7 \%$ ).

The behavioral role of money. Experimental evidence suggests that money improves cooperation through three channels: monetary exchange allows subgroups to coordinate on efficient play, the incentive to cooperate through monetary exchange does not rely on a collective punishment scheme, and the adoption of a monetary convention weakens the incentives to free ride.

Without tokens, the efficient outcome can be supported via decentralized community enforcement, but this requires a uniform convention of behavior (Kandori, 1992). Everyone in the economy must follow the same strategy both in equilibrium as well as out-of-equilibrium. This generates a formidable coordination problem because subjects have many punishment strategies to choose from, not only the threat specified in the norm of cooperation.

By contrast, monetary trade is a history-independent strategy that can discourage defections without the need to coordinate on community punishment. In a monetary equilibrium, punishment will target only the individual who defected. The seller who does not cooperate simply does not receive a token that she needs in following round to buy help. A key advantage of monetary trade is that it supports some cooperation even if not everyone in the economy adhere to the same convention. This is especially important when there is heterogeneity in strategy adoption, as it is often the case in experimental economies (Camera et al. 2012; Dal Bó and Fréchette, 2011; Fudenberg et al. 2012). For instance, a pair of subjects can adopt monetary exchange regardless of what others do. With heterogeneity in strategies, decentralized community 
enforcement is likely to fail in sustaining the efficient outcome. Consider, as an example, an economy where everyone follows a norm of cooperation except one subject, who always defects.

Experimental evidence indicate that widespread adoption of the strategy of monetary exchange also affected the incentives to cooperate by redistributing surplus from frequent defectors to frequent cooperators. Empirically, the probability of a cooperative outcome improves only for those who hold tokens and falls for everyone else, so that the use of tokens redistributes surplus in an incentive-compatible way, from defectors to cooperators (Figure 4). With money, subjects who cooperated less than $40 \%$ as sellers earned significantly less than without money while subjects who cooperated $40 \%$ or more earned significantly more (Camera and Casari, 2014).

Robustness of monetary systems. The emergence of monetary exchange in the lab does not seem to be an artifact of the specific design chosen. We manipulated the role assignment, constraints to token holdings, and available actions. In some experiments, the seller and buyer roles alternate deterministically (Bigoni et al., forth.ff) while in others they alternate randomly (Camera et al., 2013a, Camera and Casari, 2014, see Table 20. In the former case, a balance of one token per consumer is all that is needed for the monetary system to function efficiently. In the latter case, there is a precautionary motive to hold tokens. For this reason in Camera and Casari (2014) and Camera et al. (2013a) there is a double supply of tokens. Monetary exchange with random roles cannot, by design, deliver the efficient allocation. Yet, monetary exchange emerges endogenously as much as it did with deterministic roles and confirms the main results. Another variation in design are the constraints on the individual accumulation of tokens, which facilitate the emergence of a mon- 


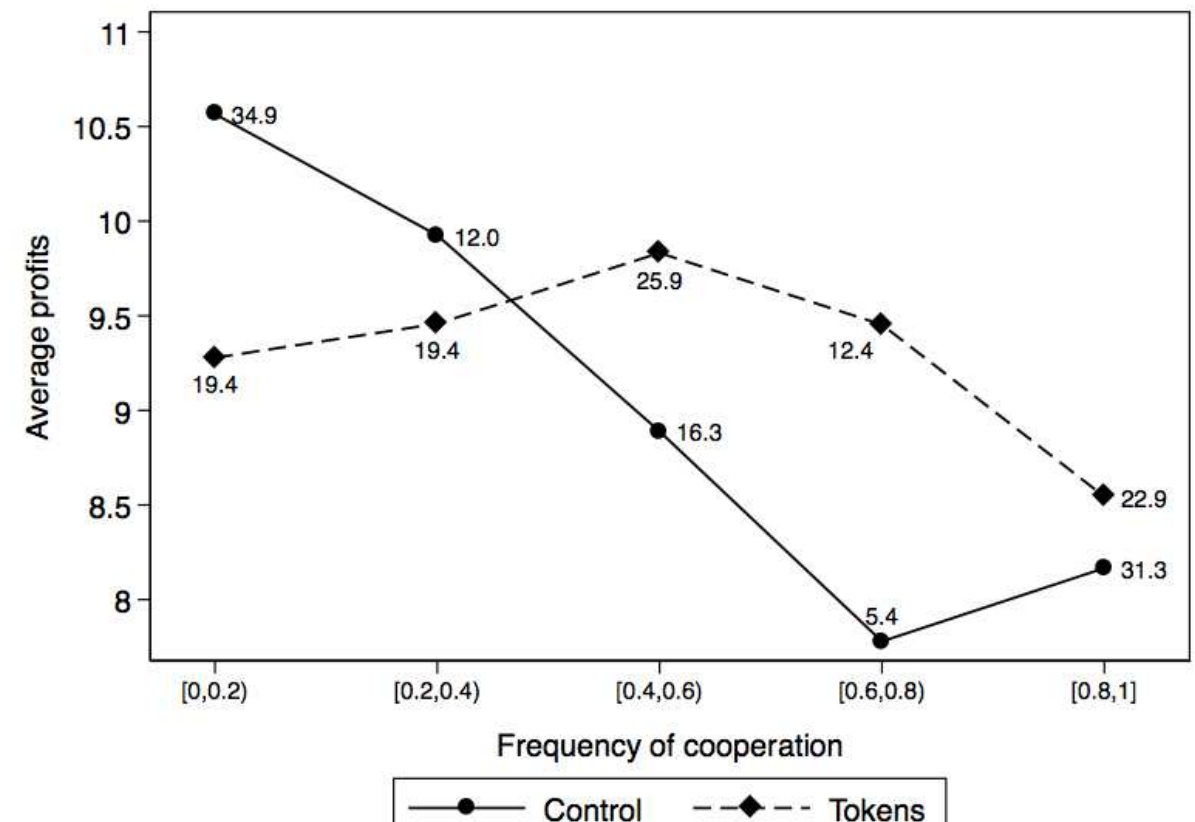

Figure 4: Cooperation rates and earnings.

Notes: Baseline (Control, $\mathrm{N}=166$ ) and Tickets (Tokens, $\mathrm{N}=170$ ) treatments from Camera and Casari (2014). Next to each data point, we report the associated percentage of observations. Experiment with $g=20, d=8, l=0, a=2$. Hence, average profit is 11 when $\mathrm{Z}$ is the outcome, i.e., $(20+2) / 2$; it is 8 when $\mathrm{Y}$ is the outcome, i.e., $(8+8) / 2$. We separately computed average profits as consumer and producer and then took their arithmetic average in order to account for the frequency of roles. Only obs. where subjects switch roles within the cycle are included. 
etary system (Camera and Casari, 2014). When we remove them, we see there is no overaccumulation of tokens in line with monetary theory (Camera et al., 2013a). Finally, we include actions involving tokens that are antithetical to monetary exchange. More precisely, we allow producers to defect conditionally on receiving a token from the consumer. Symmetrically, we allow consumers to transfer a token on the producer defecting (Bigoni et al., forth.). Here tokens may take on a negative connotation as subjects could use them to tag defectors by giving tokens to those who do not help. Given this richer action set, the addition of tokens might increase coordination problems. Subjects, in fact, almost never chose these actions (producers 3.4\%, consumers 1.4\%), and the expansion of the action set did not prevent the emergence of monetary exchange (Bigoni et al., forth.). The overall consistency of results in experiments with money provides some comfort on the replicability of the empirical results (Camerer et al., 2016).

\section{New results: oversupply of tokens}

Above we have argued that a monetary system requires ideal conditions to emerge and to function smoothly. The token supply can neither be too lowotherwise monetary trade cannot support efficiency - nor excessive - otherwise monetary trade will not be an equilibrium. Consequently, a natural question is: does monetary exchange emerge when it is not an equilibrium? For example, the mere fact that tokens are available could possibly generate an experimenter demand effect, which may thus lead to the emergence of a monetary trade convention. It is also possible that participants engage in monetary exchange in the lab just because they are used to do so in the field.

To shed some light on this issue we modify the design described in Section 4 
by oversupplying tokens to both sides of the market, producers and consumers. In the original game discussed above the tokens supply is calibrated to support an efficient allocation in monetary equilibrium. Half of the participants are consumers, have one token and spend it in each round, while the other half of participants are producers, have no tokens and earn one, alternating spending and earning one token over the course of the supergame. Here, instead, we increase the tokens supply by a factor of ten and we also change its initial distribution. In round 1, each player received five tokens, so there is initially a homogenous distribution of tokens.

Given the experimental set-up, a participant can spend tokens for a number of rounds that is longer than the expected duration of the interaction. In practice, given a random continuation probability $\beta=0.75$, each player expects the supergame to continue for 3 more rounds, and he has tokens enough to buy cooperation for ten. The incentive to sell help for one more token should thus be insufficient to support monetary exchange (see the theory section below).

For this treatment, we recruited 48 undergraduate subjects at Purdue University, involved in two sessions, run in January 2012. The experiment was programmed and conducted with the software z-Tree (Fischbacher, 2007). Instructions (a copy is in Appendix $\mathrm{C}$ of Bigoni et al. forth.) were read aloud at the start of the experiment and left on the subjects' desks. A 25-question comprehension quiz was administered electronically after the instruction round. No eye contact was possible among subjects. Average earnings were $\$ 19$ per subject $(\min =\$ 12.50, \max =\$ 26$. On average, a session lasted 106 rounds for a running time of about 1 hour and 41 minutes $(\min =99$ minutes, $\max =104$ minutes excluding instruction reading, a quiz, and payments. 
Theory. This section demonstrates that when the supply of tokens is excessive, then monetary exchange may not be an equilibrium. To this end, endow each player with $M \geq 1$ tokens in the first round of play, $t=1$. As before, monetary exchange requires that players alternate spending one token to selling for a token. Since token inventories are not observable - and there is no free disposal of tokens - we need to construct a trading strategy that removes the incentives to progressively exhaust the player's own tokens endowment, while refusing to acquire additional tokens by helping others.

Definition 3 (Monetary trade strategy with many tokens). Fix a round t. If the player is a consumer with a token, then she chooses to transfer one token upon receiving help. If the player is a producer, then she chooses to help upon receiving a token ( $i$ ) if $t$ is odd and she has no more than $M$, or (ii) if $t$ is even and she has no more than $M-1$ tokens; in all other circumstances a producer chooses "do not help."

This trading strategy is Markov and presumes that players maintain the same conduct even after a deviation is observed. If everyone adopts this strategy, then there is monetary trade because tokens are traded for help in each meeting, consumption patterns are stationary, and coincide with the efficient allocation.

Table 3: The equilibrium distribution of money with many tokens.

\begin{tabular}{lcccccc} 
Period & 1 & 2 & 3 & 4 & 5 & $\ldots$ \\
\hline Initial producer & $M$ & $M+1$ & $M$ & $M+1$ & $M$ & $\ldots$ \\
Initial consumer & $M$ & $M-1$ & $M$ & $M-1$ & $M$ & $\ldots$
\end{tabular}

In monetary equilibrium payoffs coincide with $v_{0}$ and $v_{1}$ defined earlierwhen only initial consumers are endowed with one token. Unlike the monetary equilibrium discussed earlier, the equilibrium distribution of tokens alternates across rounds and is more homogeneous. At the start of every odd round every 
player has $M$ tokens, while at the start of every even round each consumer has $M+1$ token and each producer has $M-1$. This distribution alters the incentives to participate in the monetary system, and alters the condition supporting monetary equilibrium. 11

Proposition 3 (Existence of monetary equilibrium with many tokens). Consider a group with $n=2,3, \ldots$ producers and $n$ consumers. Let each player be initially endowed with $M \geq 1$ tokens. If

$$
d+\beta\left[\frac{1}{n}\left(d-l+\beta v_{0}\right)+\frac{n-1}{n}\left(g+\beta a+\beta^{2} \tilde{v}_{1}\right)\right] \leq v_{0},
$$

where

$$
\begin{aligned}
v_{0} & =\frac{a+\beta g}{1-\beta^{2}} \\
\tilde{v}_{1} & =\frac{d-l+\beta v_{0}+(n-1)(g+\beta a)}{n-(n-1) \beta^{2}},
\end{aligned}
$$

then the monetary trade strategy in Definition 3 supports a monetary equilibrium.

Proof. To show it, we must demonstrate that no producer has a profitable one-time deviation to take, in equilibrium. Without loss in generality we can consider a producer in $t=1$. In equilibrium producers and consumer each have $M$ tokens. Suppose the producer deviates by refusing to help for a token, and then reverts back to play the strategy in Definition 3 from the following round. In $t=1$ the deviator earns $d$ instead of $a<d$, and in $t=2$ she has still $M$ tokens. On that date there are only $n-1$ producers with $M-1$ tokens because one still has $M$ tokens; this is the individual who in $t=1$ was

\footnotetext{
${ }^{11}$ One could consider history-dependent strategies involving money. For example, economywide punishment is triggered if some producer refuses to help for a token. However, this is unlike the Markov trade strategy discussed in the monetary literature, which is history independent.
} 
a consumer but could not buy help in the meeting with the deviant producer (details in Appendix).

On $t=2$ the deviator is a consumer, and reverts back to play equilibrium so the distribution of tokens depends on who she meets:

- with probability $1 / n$, in $t=2$ the deviator meets the producer with $M$ tokens and cannot trade. In $t=3$ the distribution of money is back at its equilibrium value (everyone has $M$ ).

- with probability $(n-1) / n$, in $t=2$ the deviator meets a producer with $M-1$ tokens. The deviator trades but another consumer cannot. Hence, in $t=3$ everyone has $M$ tokens but two producers: the deviator (who has $M-1)$ and the player who could not buy in $t=2($ has $M+1)$. It follows that the distribution of tokens in round $t=4$ is identical to $t=2$, where one producer and one consumer have $M$ tokens.

Since the monetary strategy is time-invariant, the payoff $\tilde{v}_{1}$ to the deviator can be recursively defined for $t=2$ as

$$
\tilde{v}_{1}=\frac{1}{n}\left(d-l+\beta v_{0}\right)+\frac{n-1}{n}\left[g+\beta\left(a+\beta \tilde{v}_{1}\right)\right] .
$$

To interpret this payoff note that the deviator enters round $t=2$ as a consumer with $M$ tokens instead of $M+1$, and reverts back to following the monetary trade strategy in Definition 3. The distribution in $t=2$ is off equilibrium. Whether or not this distributional change is temporary or not depends on matching in $t=2$. If the deviator does not consume in round $t=2$ (with probability $1 / n)$, then the tokens' distribution is back at equilibrium in $t=$ 
3 - when the deviator is once again a producer. Otherwise, the distribution of tokens evolves so that in round $t=4$ is once again identical to the offequilibrium distribution in $t=2$.

The discussion above implies that monetary trade is an equilibrium when

$$
d+\beta \tilde{v}_{1} \leq v_{0}=a+\beta\left(g+\beta v_{0}\right) .
$$

since defecting in $t=1$ gives payoff $d$ (instead of $a$ ) to the producer who deviates, and the defection changes the distribution of tokens as seen above. By the definition of $\tilde{v}_{1}$ we have (1).

Corollary 1. In our design monetary equilibrium requires $\beta>0.79$, approximately. Therefore, monetary equilibrium cannot be supported.

The corollary is proved by direct calculation of (1), where $n=4$, and noticing that in our design $\beta=0.75$.

Monetary trade does not emerge. The frequency of monetary trade drops across supergames in many tokens, while it increases in tokens, and in the last supergame it is $13.7 \%$ in the former treatment, and $74.0 \%$ in the latter, in the encounters when trade is possible. 
Table 4: Adoption of the monetary strategy "Z for 1".

\begin{tabular}{lcc}
\hline $\begin{array}{l}\text { Dep. var.: Frequency of adoption } \\
\text { of the monetary strategy }\end{array}$ & & \\
\hline Supergame & $0.049^{* * *}$ & 0.012 \\
Many Tokens & $-0.222^{* * *}$ & 0.056 \\
Many Tokens x Supergame & $-0.070^{* * *}$ & 0.016 \\
Constant & $0.877^{* *}$ & 0.370 \\
\hline N & 599 & \\
R-squared within & 0.135 & \\
R-squared between & 0.419 & \\
R-squared overall & 0.335 & \\
\hline
\end{tabular}

Notes: One observation per subject per supergame, in all supergames, but only in rounds where trade was possible. Panel regression with random effects at the individual level and robust standard errors (S.E.) adjusted for clustering at the session level. The sum of the coefficients Supergame and many tokens x Supergame is significant at the $10 \%$ level (p-value $=0.054)$. Controls include the following individual characteristics: gender, major, two measures of understanding of the instructions (response time and number of wrong answers in the quiz) and session location (Purdue, Chapman). In this experiment $g=20, d=8$, $l=0, a=2$. This regression also includes data from the Money treatment in Bigoni et al. (forth.).

The collapse of cooperation. The introduction of a dysfunctional institution compromises the ability to coordinate on a social norm of cooperation. Cooperation rates go from $47.1 \%$ without tokens, up to $71.9 \%$ with tokens, and down to $14.6 \%$ with many tokens, in the last supergame ${ }^{12}$ The statistical significance of the differences in cooperation that emerge across treatments is confirmed by the panel regressions presented in Table 5

${ }^{12}$ These numbers refer to all encounters. If we restrict our attention to encounters where trade was possible, cooperation rates are $84.9 \%$ with tokens, and $14.7 \%$ with many tokens. 
Table 5: Cooperation rate.

\begin{tabular}{|c|c|c|c|c|}
\hline Dep. var.: Frequency of cooperation & coeff. & S.E. & coeff. & S.E. \\
\hline Supergame & $-0.031^{* *}$ & 0.016 & $-0.031^{* *}$ & $\overline{0.014}$ \\
\hline Tokens & & & $-0.275^{* * *}$ & 0.069 \\
\hline Tokens x Supergame & & & $0.106^{* * *}$ & 0.019 \\
\hline Many Tokens & & & $-0.275^{* * *}$ & 0.068 \\
\hline Many Tokens x Supergame & & & 0.005 & 0.018 \\
\hline Constant & $0.308^{* *}$ & 0.127 & $0.396^{* * *}$ & 0.105 \\
\hline $\mathrm{N}$ & 360 & & 960 & \\
\hline R-squared within & 0.064 & & 0.186 & \\
\hline R-squared between & 0.259 & & 0.560 & \\
\hline R-squared overall & 0.179 & & 0.429 & \\
\hline
\end{tabular}

Notes: One observation per subject per supergame, in all supergames. Panel regression with random effects at the individual level and robust standard errors (S.E.) adjusted for clustering at the session level. The estimated coefficients for Tokens and Many tokens are not significantly different ( $\mathrm{p}$ - value $>0.100$ ). The estimated coefficients for Tokens $x$ Supergame and Many tokens x Supergame are significantly different at the $1 \%$ level (pvalue $<0.001)$. The sum of the coefficients Supergame and Many tokens $x$ Supergame is significant at the $5 \%$ level (p-value $=0.032$ ). The sum of the coefficients Supergame and Tokens $x$ Supergame is significant at the $1 \%$ level (p-value $<0.001)$. Controls are described in the notes to Table 4 This regression also includes data from the Baseline and Money (here "Tokens") treatments in Bigoni et al. (forth.)

\section{Conclusions}

This chapter adopts theoretical methods and laboratory experiments to study the economic outcomes and the patterns of cooperation that emerge in groups of strangers. It contributes to experimental game theory along three lines: first, it presents a setup - called the Intertemporal Exchange Game-designed to capture long-run strategic interaction among strangers. Second, it shows how monetary systems, which are usually analyzed from a non-strategic perspective in macroeconomics, can be studied within this game-theoretical framework. Third, it shows how to bring this theoretical setup to the lab, in order 
to understand why money exists and how it impacts allocations. This is done by contrasting a laboratory setting where a fiat monetary system can spontaneously emerge to one where it cannot.

To study the behavioral role of money, we design the environment in such a way that relying on monetary exchange is theoretically inessential to attain high-payoffs. We find that in the laboratory, the emergence of a monetary system generates a variety of behavioral effects: (i) it enables groups of players to sustain cooperation without relying on a collective punishment scheme; (ii) it makes cooperation possible in subgroups; (iii) it makes free riding less profitable.

What is the benefit of adopting a monetary system to support cooperation, instead of relying on informal social norms of cooperation? In the case of a social norm, the incentive to engage in efficient play comes from the threat of community-wide punishment. Although this threat is never carried out in equilibrium, it makes cooperation inherently fragile because even just one accidental deviation can permanently set cooperation off-course. This fragility is a necessary ingredient because it is precisely what provides the incentive to cooperate in the first place. A second issue is that the punishment threat implicit in the social norm must be credible. This means there must be a shared belief that everyone in the community will follow through with the sanction, when punishment is called for. The credibility of this threat is also fragile because the social norm is based on a collective form of punishment, and not everyone may consider this kind of punishment a fair response to an isolated defection. In fact, we rarely observe full cooperation in the lab, even if cooperation through community-wide enforcement is well within the theoretical bounds.

The advantage of monetary trade over a social norm of cooperation of the 
kind discussed above, is that it makes cooperation incentive-compatible without making it fragile. In a monetary system strategies are history-independent and do not involve a collective switch in behavior in response to isolated defections. Only probable defectors - those who do not have money - are sanctioned, and not the entire society. This unique feature of monetary exchange not only simplifies the implementation and the credibility of enforcement, but it also ensures a greater resilience of cooperation. In a monetary economy groups can quickly recover from an occasional defection.

Another advantage of monetary trade, compared to social norms, comes from its ability to better handle the heterogeneity in strategy adoption that is typically observed in the laboratory. Monetary exchange can support partial cooperation, when not everyone in the group acts cooperatively. This constitutes a significant behavioral strength because it allows a subset of community members - those interested in cooperation - to attain reasonable payoffs by relying on monetary exchange among themselves, while ignoring those who do not use money. It also provides clear incentives to those who are not cooperating, as monetary exchange ensures an incentive-compatible redistribution of surplus from frequent defectors (who do not have money) to frequent cooperators (who have money). By contrast, heterogeneity in strategies is orthogonal to the use of decentralized community enforcement, which by definition requires uniform behavior. 


\section{References}

Aliprantis, C.D., and C. Plott. 1992. Competitive Equilibria in Overlapping Generations Experiments. Economic Theory 2, 389-426.

Abreu, D., D. Pierce and E. Stacchetti . 1990. Toward a Theory of Discounted Repeated Games with Imperfect Monitoring. Econometrica, 58, 1041-1063.

Basu, S., Dickhaut, J., Hecht, G., Towry, K., and Waymire, G. 2009. Recordkeeping alters economic history by promoting reciprocity. Proceedings of the National Academy of Sciences, 106(4), 1009-1014.

Bigoni, Maria and Camera, Gabriele and Casari, Marco. 2019. Partners or Strangers? Cooperation, monetary trade, and the choice of scale of interaction. American Economic Journal: Microeconomics (forthcoming).

Bigoni, M., Camera, G., and Casari, M. 2019a. Money is More than Memory. Journal of Monetary Economics (forthcoming).

Bolton, G. E., Katok, E., and Ockenfels, A. 2005. Cooperation among strangers with limited information about reputation. Journal of Public Economics, 89(8), 1457-1468.

Camera, G. 2017. A perspective on electronic alternatives to traditional currencies. Sveriges Riksbank Economic Review 1, 126-148.

Camera, G. and Casari, M. 2009. Cooperation among strangers under the shadow of the future. American Economic Review, 99(3), 979-1005.

Camera, G. and M. Casari. 2014. The Coordination Value of Monetary Exchange: Experimental Evidence. American Economic Journal: Microeconomics 6(1), 290-314.

Camera, G. and Casari, M. 2017. Monitoring institutions in indefinitely repeated games. Experimental Economics.

Camera, G., M. Casari, and M. Bigoni. 2012. Cooperative strategies in anonymous economies: an experiment. Games and Economic Behavior 75, 570586.

Camera, G., M. Casari, and M. Bigoni. 2013a. Money and trust among strangers. Proceedings of the National Academy of Sciences, 110(37), 1488914893. 
Camera, G., M. Casari, and M. Bigoni. 2013b. Experimental Markets with Frictions. Journal of Economic Surveys 27(3), 536-553.

Camera, G., C. Deck, and D. Porter. 2016. Do Economic Inequalities Affect Long-Run Cooperation \& Prosperity? Working paper, Economic Science Institute, Chapman University.

Camera, G, and A. Gioffré. Game-Theoretic Foundations of Monetary Equilibrium. Journal of Monetary Economics, 2014.

Camera, G., C. Noussair, and S. Tucker. 2003. Rate of return dominance and efficiency in an experimental economy. Economic Theory, 22, 629-660.

Camera, G., and F. Vesely. 2007. Trading horizons and the value of money. European Economic Review 51(7), 1751-1767.

Camerer, Colin F., Anna Dreber, Eskil Forsell, Teck-Hua Ho, Juergen Huber, Magnus Johannesson, Michael Kirchler, Johan Almenberg, Adam Altmejd, Taizan Chan, Emma Heikensten, Felix Holzmeister, Taisuke Imai, Siri Isaksson, Gideon Nave, Thomas Pfeiffer, Michael Razen, Hang Wu. 2016. Evaluating replicability of laboratory experiments in economics. Science, 351(6280): 1433-1436.

C. Monica Capra, Tomomi Tanaka, Colin F. Camerer, Lauren Feiler, Veronica Sovero and Charles N. Noussair. 2009. The impact of simple institutions in experimental economies with poverty traps. Economic Journal, 119, 9771009 .

Corbae, D., T. Temzelides, and R. Wright. 2003. Directed matching and monetary exchange. Econometrica, 71(3), 731-756.

Dal Bó, P. 2005. Cooperation under the Shadow of the Future: Experimental Evidence from Infinitely Repeated Games. American Economic Review, 95(5), 1591-1604.

Dal Bó, P. and G. Fréchette. 2011. The Evolution of Cooperation in Infinitely Repeated Games: Experimental Evidence. American Economic Review, 101(1), 411-429.

Deck, C.A., K.A. McCabe, and D. Porter. 2006. Why stable fiat money hyperinflates: Results from an experimental economy. Journal of Economic Behavior \& Organization 61, 471-486.

Diamond, P. 1984. Money in Search Equilibrium. Econometrica, 52(1), 1-20. 
Duffy, J. and J. Ochs. 2002. Intrinsically worthless objects as media of exchange: Experimental evidence. International Economic Review, 43, 637673.

Duffy, J. and J. Ochs. 2009. Cooperative Behavior and the Frequency of Social Interaction. Games and Economic Behavior, 66, 785-812.

Duffy J., and D. Puzzello, 2014. Gift Exchange versus Monetary Exchange: Theory and Evidence. American Economic Review, 104(6), 1735-1776.

Ellison, Glenn. 1994. Cooperation in the prisoner's dilemma with anonymous random matching. Review of Economic Studies, 61, 567-88

Fehr, Ernst and Simon Gächter. 2000. Fairness and Retaliation: The Economics of Reciprocity. Journal of Economic Perspectives 14(3), 159-181.

Fischbacher, U. 2007. Z-Tree: Zurich toolbox for ready-made economic experiments, Experimental economics 10(2), 171-178.

Friedman, J. W., 1971. A Non-cooperative Equilibrium for Supergames. Review of Economic Studies, 38(1), 1-12.

Fudenberg, D., G.D. Rand, and A. Dreber. 2012. Slow to anger and fast to forgive: Cooperation in an uncertain world. American Economic Review, 102(2), 720-749.

Fudenberg, D. and E. Maskin. 1986. The Folk Theorem in Repeated Games with Discounting or with Incomplete Information. Econometrica, 50, 533554.

Graeber, David, 2011. Debt: the first 5000 years. Melville, New York.

Greif, Avner. 2006. The Birth of Impersonal Exchange: The Community Responsibility System and Impartial Justice. Journal of Economic Perspectives, 20(2), 221-236.

Hahn, Frank. 1973. On Transaction Costs, Inessential Sequence Economies and Money. Review of Economic Studies, 449-461

Hayashi, F., and A. Matsui. 1996. A Model of Fiat Money and Barter. Journal of Economic Theory 68, 111-132 .

Heinemann, F., R. Nagel and P. Ockenfels. 2009. Measuring Strategic Uncertainty in Coordination Games. Review of Economic Studies 76, 181-221 
Hellwig, M.F. 1976. A Model of Monetary Exchange, Working paper, Princeton University. https://www.princeton.edu/ erp/ERParchives/ archivepdfs/M202.pdf

Huber, J., M. Shubik, and S. Sunder. 2014. Sufficiency of an Outside Bank and a Default Penalty to Support the Value of Fiat Money: Experimental Evidence. Journal of Economic Dynamics and Control 47, 317-337

Huggett M., and S. Krasa. 1996. Money and storage in a differential information economy. Economic Theory 8, 191-209.

Humphrey, Caroline. 1985. Barter and Economic Disintegration. Man, 20(1), 48-72.

Isaac, R., J.M. Walker, and, A.W. Williams. 1994. Group size and the voluntary provision of public goods: Experimental evidence utilizing large groups. Journal of Public Economics, 54(1), 1 - 36.

Kahn, C.H., McAndrews, J., and W. Roberds. 2005. Money is privacy. International Economic Review, 46(2),377-399.

Kandori, Michihiro. 1992. Social norms and community enforcement. Review of Economic Studies, 59, 63-80.

Keynes, John Maynard. 1936. The General Theory of Employment, Interest and Money. San Diego : Harcourt Brace (1964 ed.).

Kiyotaki, Nobuhiro, and Randall Wright. 1989. On Money as a Medium of Exchange. Journal of Political Economy, 97, 927-954.

Kocherlakota, N.R., 1998. Money is memory. Journal of Economic Theory, 81, $232-251$

Kovenock, D., and C.G. De Vries. 2002. Fiat Exchange in Finite Economies. Economic Inquiry, 40(2), 147-157.

Levine, D. and W. Pesendorfer. 1995. When are Agents Negligible? American Economic Review 85(5) 1160-1170

Lian, Peng and Plott, Charles R. 1998. General equilibrium, markets, macroeconomics, and money in a laboratory experimental environment. Economic Theory, 12 (1), 21-75. 
Mankiw, G. 2004. Principles of Economics. Thomson South Western, Third Edition.

Marimon, R., and S. Sunder. 1993. Indeterminacy of equilibria in a hyperinflationary world: Experimental evidence. Econometrica, 61 (5), 1073-1107.

Marimon, R., and S. Sunder. 1994. Expectations and learning under alternative monetary regimes: An experimental approach. Economic Theory 4(1), 131162.

McCabe, K., S. Rassenti, and V. Smith. 1998. Game Theory and Reciprocity in Some Extensive Form Experimental Games. Proceedings National Academy of Science, 93, 13421-13428.

McCabe, K. A. 1989. Fiat money as a store of value in an experimental market. Journal of Economic Behavior $\&$ Organization, 12(2), 215-231.

Nosenzo, D., S. Quercia, and M. Sefton. 2015. Cooperation in small groups: the effect of group size. Experimental Economics, 18(4), 4-14.

Nowak, M. A. and K. Sigmund. 1998. Evolution of indirect reciprocity by image scoring. Nature, 393(6685), 573-577.

Offerman, T., J. Potters, and H.A. Verbon. 2001. Cooperation in an overlapping generations experiment. Games and Economic Behavior, 36(2), 264275.

Ostrom, E., 2010. Beyond markets and states: polycentric governance of complex economic systems. American Economic Review 100, 641-672.

Ostroy, J.M. 1973. The Informational Efficiency of Monetary Exchange. American Economic Review, 63(4), 597-610

Ostroy, J.M., R.M. Starr. 1990. The Transactions Role of Money. Handbook of Monetary Economics, vol. 1, Benjamin M. Friedman and Frank H. Hahn, eds., Elsevier Science Publishers, 3-62.

Palfrey, T.R. and H. Rosenthal. 1994. Repeated Play, Cooperation and Coordination: An Experimental Study. The Review of Economic Studies, 61(3), 545-565.

Plott, C. 2001. Equilibrium, Equilibration, Information and Multiple Markets: From Basic Science to Institutional Design. Nobel Symposium on Behavioral and Experimental Economics, Stockholm, Sweden. 
Polanyi, K., The semantic of money uses. Reprinted in Primitive, archaic and modern economies: essays of Karl Polanyi (1957).

Roth, Alvin E., and Keith Murnighan. 1978. Equilibrium behavior and repeated play of the prisoner's dilemma. Journal of Mathematical Psychology, $17,189-98$

Rubinstein, A. 1979. Equilibrium in Supergames with the Overtaking Criterion. Journal of Economic Theory, 21, 1-9.

Samuelson, P.A. 1958. An Exact Consumption-Loan Model of Interest with or without the Social Contrivance of Money. Journal of Political Economy, 66(6), 467-482.

Shapley, Lloyd and Martin Shubik. 1977. Trade Using One Commodity as a Means of Payment. Journal of Political Economy 85(5), 937-968

Stahl, D. O. 2013. An experimental test of the efficacy of a simple reputation mechanism to solve social dilemmas. Journal of Economic Behavior 86 Organization, 94(0), 116-124.

Starr, R. M. 1972. The Structure of Exchange in Barter and Monetary Economies. Quarterly Journal of Economics, 86(2), 290-302.

Townsend, R., 1980. Models of money with spatially separated agents. In: Kareken, J., Wallace, N. (eds.) Models of monetary economies, 265-303. Minneapolis: Federal Reserve Bank of Minneapolis

Townsend, R., 1987. Economic Organization with Limited Communication. American Economic Review, 77 (5), 954-971

Van Huyck, J., R. Battalio, and R. Beil, 1990. Tacit Coordination Games, Strategic Uncertainty, and Coordination Failure. Am. Econ. Rev. 80, 234248.

Wallace, Neil. 2014 . Optimal money creation in "pure currency" economies: a conjecture. The Quarterly Journal of Economics 129(1), 259-274. 


\section{Appendix}

\section{A. The distribution of tokens off-equilibrium}

On $t=2$ the tokens' distribution is off equilibrium as illustrated in the figure below. In particular, the deviator has $M$ tokens unlike all other consumers who have $M+1$. The deviator reverts back to play equilibrium in $t=2$. In period $t=3$ the distribution of tokens will depend on who she meets in period $t=2$.

With probability $1 / n$ the deviator is matched to the producer who has $M$ tokens. This is the same person who met the deviator in $t=1$. That producer does not sell, according to the monetary trade strategy in Definition 3. so the deviator cannot spend a token in $t=2$ and earns $d-l$. Hence, in $t=3$ the distribution of money is back at its equilibrium value, since every individual will have $M$ tokens. Therefore, on $t=3$ the continuation payoff for the deviator is $v_{0}$.

Table 6: Off-equilibrium token distribution if deviator can trade in $t=2$.

\begin{tabular}{lccccc} 
& \multicolumn{5}{c}{ Period } \\
Initial role & 1 & 2 & 3 & 4 & $\ldots$ \\
\hline Producer & & & & & \\
$\quad$ deviator & $M$ & $M$ & $M$ & $M+1$ & $\ldots$ \\
$\quad$ other & $M$ & $M+1$ & $M$ & $M+1$ & $\ldots$ \\
$\quad$ other $n-2$ & $M$ & $M+1$ & $M$ & $M+1$ & $\ldots$ \\
Consumer & & & & & \\
$\quad$ meets deviator & $M$ & $M$ & $M$ & $M-1$ & $\ldots$ \\
other & $M$ & $M-1$ & $M$ & $M-1$ & $\ldots$ \\
$\quad$ other $n-2$ & $M$ & $M-1$ & $M$ & $M-1$ & $\ldots$
\end{tabular}

Notes: With probability $1 / n$ the deviator cannot trade in $t=2$. A red color denotes off-equilibrium token holdings.

With probability $(n-1) / n$ the deviator — who has $M$ tokens unlike all other 
consumers (who have $M+1$ )-is matched to some producer who has $M-1$ tokens. Hence, the deviator spends a token and earns $g$. This means that one consumer who has $M+1$ cannot trade-she meets the producer who has $M$. The distribution of tokens in round $t=3$ thus is as follows: everyone has $M$ tokens with the exception of two producers, one of which is the deviator (with $M-1$ tokens) and the other is the person who could not buy in $t=2$ (has still $M+1$ tokens). See the figure below.

This second producer will not sell for a token on $t=3$. The deviator, instead, will produce because she has reverted back to play equilibrium. She will earn $a$ in round $t=3$. Hence, on $t=3$ again we have some consumer who will not trade and the distribution of tokens in round $t=4$ is back to the off-equilibrium distribution we had in round $t=2$.

Since the monetary strategy is time-invariant, the continuation payoff to the deviator must be the same as it was in $t=2$, and can be defined as $\tilde{v}_{1}$.

Table 7: Off-equilibrium token distribution if deviator cannot trade in $t=2$.

\begin{tabular}{lccccc} 
& \multicolumn{5}{c}{ Period } \\
Initial role & 1 & 2 & 3 & 4 & $\ldots$ \\
\hline Producer & & & & & \\
$\quad$ deviator & $M$ & $M$ & $M-1$ & $M$ & $\ldots$ \\
other & $M$ & $M+1$ & $M+1$ & $M+1$ & $\ldots$ \\
$\quad$ other $n-2$ & $M$ & $M+1$ & $M$ & $M+1$ & $\ldots$ \\
Consumer & & & & & \\
$\quad$ meets deviator & $M$ & $M$ & $M$ & $M-1$ & $\ldots$ \\
other & $M$ & $M-1$ & $M$ & $M$ & $\ldots$ \\
other $n-2$ & $M$ & $M-1$ & $M$ & $M-1$ & $\ldots$
\end{tabular}

Notes: With probability $(n-1) / n$ the deviator cant trade in $t=2$. A red color denotes off-equilibrium token holdings. 